\title{
Leadership Qualities of a Modern University Student in the Reflexive Dimension
}

\author{
Viktoria Zhelanova \\ Pedagogical Institute \\ Borys Grinchenko Kyiv University \\ I.Shamo Blvd 18/2, 02154 Kyiv \\ Ukraine \\ e-mail: v.zhelanova@kubg.edu.ua \\ Svitlana Palamar \\ Pedagogical Institute \\ Borys Grinchenko Kyiv University \\ I.Shamo Blvd 18/2, 02154 Kyiv \\ Ukraine \\ e-mail: svetlana_03@ukr.net \\ Maryna Yepikhina \\ Pedagogical Institute \\ Lugansk National Taras Shevchenko University \\ Hoholia Square 1, 92700 Starobilsk \\ Ukraine \\ e-mail: dewdrop@ukr.net
}

\begin{abstract}
Leadership qualities of the individual are of particular importance in the context of globalization and integration trends of modern society. Leadership is the inner state of a person determining the strategy of her life. Thus, leadership qualities are related to its reflection, which gives the opportunity to carry out introspection and to analyze other people, that is meta quality. This circumstance makes it possible to consider the phenomenon of leadership qualities of students in the reflexive dimension. Leadership qualities of a modern University student have a complex structure, contains motivational-value, cognitive, operational-activity components. These components are associated with different types of reflection, namely, personal, intellectual, communicative, cooperative; retrospective, situational, perspective. The diagnostic tools presented in the article allowed to determine the level of formation of students' leadership qualities and their reflexivity and to statistically prove the relationship and interrelation of these phenomena. At the initial stage of education at the University dominated by leadership qualities of the individual, focused "on themselves" and, accordingly, personal, intellectual and retrospective types of reflection. At the stage of completion of the second (bachelor) level of higher education the priority is given to leadership qualities of the student, aimed "at others", which are determined by communicative, cooperative, perspective reflection. The results of the experimental study actualized the need for the formation of leadership qualities and different types of reflection of modern University students.
\end{abstract}

\section{Introduction}

Globalization and European integration trends in the development of all parts of modern society predetermine the necessity and feasibility of the strategy of modernization of professional training of future specialists in the higher education system in the direction of its competent, student-centered dimensions. This format of higher education is focused on the priority of the formation of the system of competencies and personal qualities of the student. It is worth noting that the professional and personal qualities of the student are synthesized in his leadership qualities, which are accumulated in the phenomenon of leadership. That is why an important task of a modern institution of higher education is the formation of leaders of a new generation. In addition, the student age is associated with "high educational level, high cognitive motivation, the highest social activity and a fairly harmonious combination of intellectual and social maturity" (Zimnyaya 2004), is characterized by changes in self-consciousness, restructuring of the emotional and volitional way of life, the flowering of value and semantic sphere. It is obvious that student age is sensible to the formation of leadership qualities of the individual. Confirmation of this conclusion is the fact of introduction into scientific dicourse of the concept of "student leadership" (Savytska 2016). 
The complexity and diversity of the phenomenon of leadership stated the American psychologist Stogdill, which proved that there are as many definitions of leadership as there are people, who tried this phenomenon to be addressed (Stogdill 1974). The study of domestic and foreign heritage has given grounds to differentiate the basic approaches to the interpretation of leadership, namely: social, managerial and competence. According to the social approach, leadership is understood as a socio-psychological phenomenon, as the interaction of the leader and followers, as a process of stimulating the group to achieve common goals, as a mechanism for the integration of the group. According to the management approach, leadership is interpreted as power, as a management paradigm, as a position in society. Consonant with the competence approach, leadership is interpreted as a characteristic of behavior, the quality of personality, the ability to influence the individual and the group.

Known and a more detailed systematization of approaches to understanding leadership (Volkivska 2016), represented by its contexts: a social phenomenon, a human activity, the power of the individual, the ability to influence, characteristic behaviour, quality of personality, the process of stimulation, a means of self-organization of groups, position in society. Taking into account the indicated approaches to the understanding of leadership, we must pay attention to the reflexive nature of leadership. Therefore, we consider it appropriate to focus on the aspect associated with the interpretation of leadership as a quality of personality. At the same time, given that reflection is a meta-personality, permeates and determines all others, it is advisable to focus on the reflective aspects of leadership.

\section{Basic categories of research}

The etymology of the concept of leadership ("leader"), which is basic in the submitted study, is associated with the Anglo - Saxon root "lead" (translated - "way"). Hence "leadership" means "leading". Note that the term "leadership" has several interpretations. Thus, in encyclopedic sociological dictionary, it is the driving position of the individual or social group, which is due to the most efficient outcomes (economic, political, scientific, sporting, etc), as well as the processes of internal self-organization and self-administration group due to the individual initiative of their members (Sociology: short encyclopedic dictionary subject). However, in our opinion, it is the reflexive dimension of leadership that is reflected in its definition as a complete, authentic human expression that works to achieve a meaningful goal, which positively affects the transformation (Owen 2005). Therefore, leadership is an internal state of a person that determines a certain strategy of her life, focused on success in making certain decisions and their implementation, self-knowledge and positive self-perception and acceptance of "others", self-actualization and self-improvement, collaborative activity. Based on this position, as well as on established approaches to the structure of personality, we understand the leadership qualities of the student as the integration of individual and socio-psychological features and traits that contribute to its implementation as a leader.

Focusing on the reflexive aspects of leadership, we focus on the essence of the phenomenon of reflection. In the modern interpretation, reflection is a complex, multifunctional interdisciplinary phenomenon studied in philosophy, psychology and pedagogy. Synthesizing the approaches of these sciences, reflection is defined as the appeal of the individual to himself (to his consciousness, thinking, results of activity, to the perception of himself through the eyes of other people), which appears in the context of reflexive consciousness, reflexive thinking, reflexive activity, reflexive communication as a synthetic reality, which is a process, property and state (Zhelanova 2017). The cognitive component includes reflection as self-understanding; affective - as attitude; behavioural - as the self-regulation of behavior; social and perceptual - as a basis for adequate perception and understanding of others. So reflection performs the functions of understanding, self-knowledge, forms of theoretical activity, the principle of thinking, the category of consciousness, the basis of communication and perception.

The complexity, polyfunctionality, procedural nature of the phenomenon of reflection is reflected in its numerous classifications and types. In the context of the problem of this article, the typology of reflection, presented in the study of Semenov and Stepanov (1985), containing cooperative, communicative, personal, intellectual types of reflection is appropriate. At the same time, under the cooperative reflection, scientists understand the exit of the subject from the process of joint activity to an external position in relation to it in order to analyze its procedural and productive features, identify the causes of difficulties in it, correct the image of activity. Communicative reflection is interpreted by well-known reflexive psychologists as a process of reflection by one person of the inner world of another person; reflection here acts as the subject's awareness of how he is perceived by the communication partner. Personal reflection, according to Semenov and Stepanov, is the ability of a man to analyze and understand themselves and their subject-social relations with the outside world. Intellectual reflection is interpreted by them as the ability of the subject to allocate, analyze and relate to the objective situation of their own actions. (Semenov and Stepanov 1985).

Therefore, the outlined positions give grounds to state that cooperative reflection contributes to coordinated joint activities. This type of reflection itself ensures the formation of leadership as a partnership.

Therefore, Blanshar (2008), understands leadership as a partnership that involves mutual trust between two people who work together to achieve shared goals. Communicative reflection is based on interpersonal 
communication and is related to leadership as interpersonal interaction. Drucker (2008) defines leadership as interpersonal interaction, insisting that it is manifested in a particular situation using the communication process and aimed at achieving specific goals or objectives. Personal reflection allows a person to understand his inner world. Intellectual reflection is the analysis of the foundations of their own thinking. We would note, that cooperative and communicative reflection is inter-psychical types of reflection, oriented "on the other". Personal and intellectual reflection are intrapsychic types of reflection as the ability to isolate, perceive and analyze their own qualities.

According to the time criterion reflection is divided into situational, retrospective and perspective. Thus situational reflection assumes self-control of behavior in an actual situation, ability of the person to correlate the actions with a situation. Retrospective reflection is the analysis of past events, already performed activities. Perspective reflection is associated with the analysis of upcoming activities, behavior, as well as planning, forecasting their likely results (Karpov 2012).

Given the specifics of the leading activities of University students, we note that the formation of reflective aspects of leadership qualities of the individual is associated with the process of professionalization, as well as professional reflection. In our approaches to understanding the concept of "professional reflection" we are based on the ideas of aspect-activity approach. From these positions, we define professional reflection as an activity aimed at the analysis and awareness of their professional and personal qualities (in particular, leadership), to understand how a person is perceived by others; self-regulation and adjustment of their own activities and the object of professional activity, as well as the development of technologies for future professional activity.

\section{Student's leadership qualities in the modern university: a reflective dimension}

In modern science, there are different positions to interpret the structure of students ' leadership qualities of and highlight their list. So Sopivnyk (2012) distinguishes three groups of leadership qualities, namely: 1) general managerial (professional competence, practical thinking, communicativeness, organizational abilities, diligence, willpower, healthy lifestyle, stress resistance, collectivism); 2) leadership (charisma, creativity, initiative, empathy, morality); 3) industry-specific. There is a well-known approach according to which the structure of leadership qualities of a future specialist contains motivational-value, integrative-activity, directional-activity emotional-reflexive components (Romanovsky 2017).

The author's interpretation of the structure of modern student's leadership qualities involves the isolation in it of motivational-value, cognitive, operational-activity components.

The motivational-value component contains a value-based attitude to leadership; propensity for leadership, personal interest in it; installation for realization of leadership qualities; motives for leadership; humanistic orientation, orientation to the interests of the student's group, the university; value attitude towards, empathy with other people; optimistic life strategy. The reflexive dimension of the motivational-value component of leadership is linked to an awareness of its value hierarchy, its dynamics and reorientation; with an analysis of his leadership style. These components of leadership are ensured through personal, retrospective and situational reflection. An aspect of this component of leadership that reflects the value attitude of others is realized in the process of communicative and situational reflection, which allows one to realize the other and to form a need to empathize with him. Setting on the realization of leadership qualities is associated with personal, intellectual and perspective types of reflection. Because the installation differs from the motives and needs of sustainability and future orientation.

The cognitive component of leadership is related to knowledge about the phenomenon of leadership (nature, structure, styles, image of the image of an effective leader), as well as leadership qualities and opportunities to realize them in a particular situation; with knowledge of the student's own capabilities in forming leadership qualities. Reflexive aspects of the cognitive component cause knowledge of leadership qualities bases (personal reflection); knowledge of introspective review of their intellectual activity, knowledge of the their knowledge and ignorance limits of their leadership qualities (intellectual reflection); knowledge of the other person's inner world, knowledge of others' awareness of themselves (communicative reflection); knowledge of the organization and position of participants in group interaction (cooperative reflection).

The operational-activity component involves the practical realization of leadership qualities in effective leadership activities; ability to partner with a student group; mastering organizational, creative, professional leadership skills; the ability to generate new ideas and innovate; the ability to antitake, that is, to predict and predict the results of leadership. Reflexive dimensions of the operating component are linked to an awareness of the mechanisms of one's leadership (personal, retrospective reflection); with the analysis of its strengths and weaknesses (intellectual, situational reflection); by comparing the assessment of a student's leadership qualities with another person's self-esteem. This component of leadership qualities is of a referential nature, since leadership is realized only in group conditions. Therefore, it is based mainly on the cooperative type of reflection. 


\section{Diagnostics of university students' leadership qualities and reflection}

In order to determine students' leadership qualities in their reflexive dimension, a diagnostic toolkit was presented by a number of standardized techniques.

- Diagnosis of leadership skills by Zharykov and Krushelnytsky (Fetiskin et al. 2002). The purpose of the method: to identify the degree of students` leadership qualities development. The test questionnaire contains 50 statements that must be answered "yes" or "no"

- Methods of determining the reflection level by Anisimov (2008). The purpose of the methodology, consisting of eight questions, is to determine the individual's reflexivity, collectivity, self-criticism. The logic behind using this technique in this study is related to the diagnosis of personal and cooperative types of reflection.

- Research methodology of reflective thinking by Pashukova (Pashukova 1996 et al.). The purpose of the method: to determine the level of reflective thinking with 15 anagrams. This technique allowed us to determine the student's intellectual reflection.

- The technique of determining the reflexivity level according to Karpov (2012) was used by us to determine communicative, as well as retrospective, situational and perspective reflection. The test questionnaire contains 27 statements that need to be answered in the following ways: absolutely false, false, faster false, do not know, faster true, true and absolutely true.

These diagnostic methods were conducted among the applicants for the first (bachelor) level of higher education in the specialty 013 "Primary Education" of the Borys Grinchenko Kyiv University and the State Institution "Lugansk National Taras Shevchenko University". In total, 47 first and 41 fourth year students were surveyed. The results of the study are shown by Fig. 1.

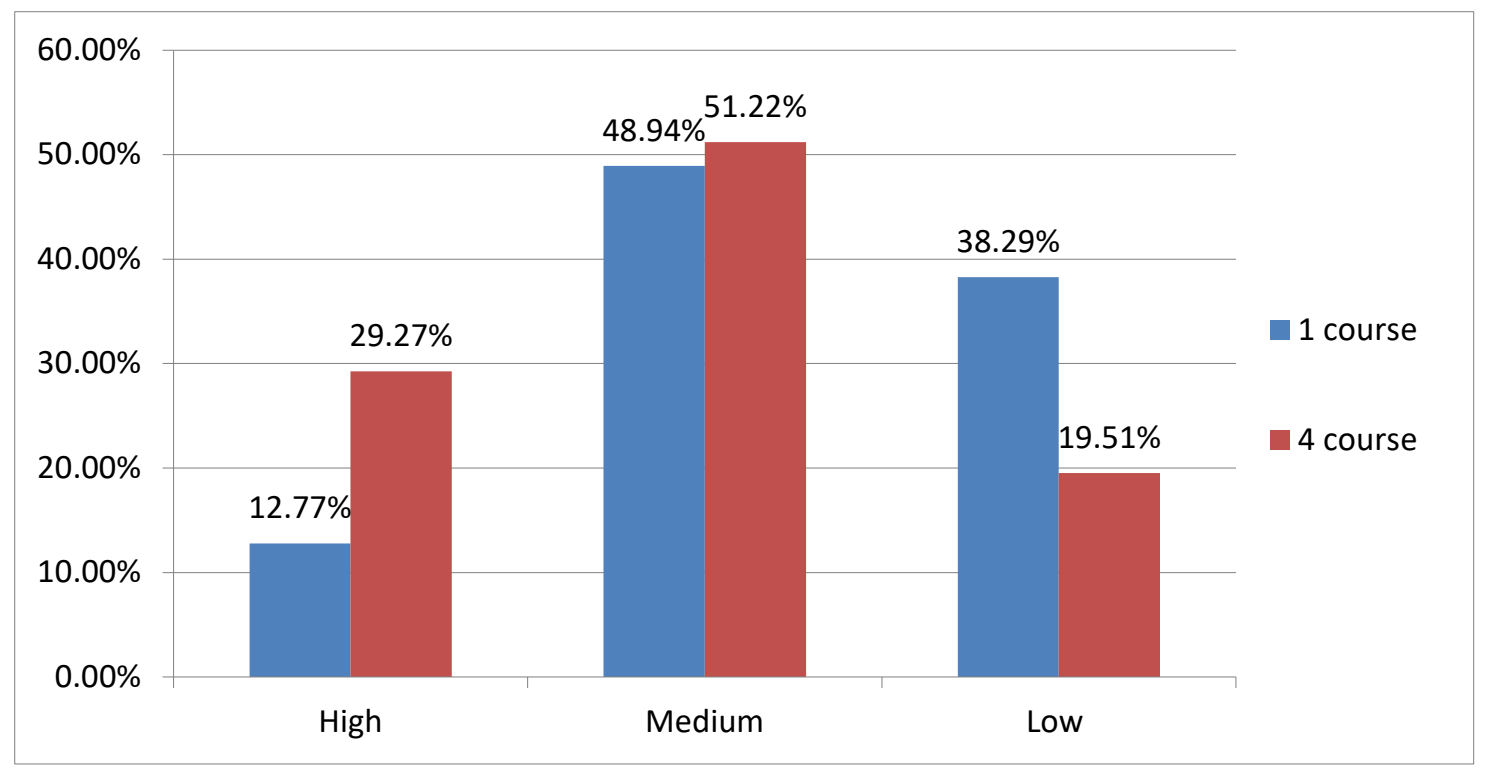

Fig. 1. Analysis of first and fourth year students` leadership qualities Source: Own results

$12.77 \%$ of the first-year students and $29.27 \%$ of the fourth-year students found a high level of leadership skills formation. The average level is observed in $48.94 \%$ of first year students and $51.22 \%$ in fourth year. $38.29 \%$ of first-year students and $19.51 \%$ of fourth-year students were diagnosed with low levels of leadership.

The analysis of the obtained results made it possible to state that the fourth-year students have leadership qualities expressed more than those of the first-year students, that is, in the process of education at the HSE students have a positive dynamics of leadership development.

The results of the study of the level of students 'reflection are shown in table 1 . On the scale of intellectual reflection the following data were obtained: a low level was detected in $31.91 \%$ of first year students and in $21.95 \%$ of representatives of the fourth year, the average level was diagnosed in $59.58 \%$ first-year students and $53.66 \%$ of fourth-year students, a high level is observed in $8.51 \%$ of first-year students and $24.39 \%$ of fourth-year students.

The analysis of the results obtained on the scale of cooperative reflection leads to the conclusion that $6.38 \%$ of first year students and $2.44 \%$ of fourth year students have a low level, a level below the average was diagnosed in $48.94 \%$ of first year students and $12.20 \%$ of students of the fourth year, $34.04 \%$ of the first year students and $53.65 \%$ of the fourth year were diagnosed with the average level of development of cooperative reflection, the level above the average was observed in $12.20 \%$ of the students of the fourth year, and was not detected in the first 
year students. The high level of co-operative reflection formation is observed in $10.64 \%$ of the first year students and $19.51 \%$ of the fourth year student

Table 1. Analysis of first and fourth year students 'reflection formation

\begin{tabular}{|c|c|c|c|c|c|c|c|c|c|c|}
\hline & \multicolumn{2}{|c|}{ Low } & \multicolumn{2}{|c|}{$\begin{array}{l}\text { Lower than } \\
\text { average }\end{array}$} & \multicolumn{2}{|c|}{ Average } & \multicolumn{2}{|c|}{$\begin{array}{l}\text { Higher } \\
\text { than average }\end{array}$} & \multicolumn{2}{|c|}{ High } \\
\hline Scale & 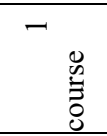 & 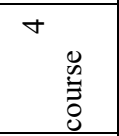 & 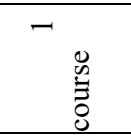 & 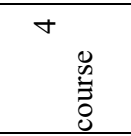 & $\begin{array}{r}-1 \\
0 \\
\stackrel{0}{0} \\
\delta \\
\delta\end{array}$ & 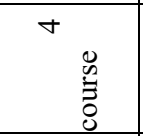 & $\begin{array}{r}-7 \\
0 \\
0 \\
\vdots \\
\vdots \\
0 \\
\end{array}$ & 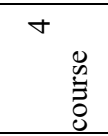 & 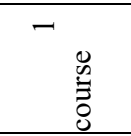 & 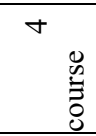 \\
\hline Intelligent & $1,91 \%$ & $1,95 \%$ & & 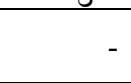 & $9,58 \%{ }^{5}$ & $3,66 \%{ }^{5}$ & & & ,51\% & 4,39 \\
\hline Cooperative &, $38 \%$ &, $44 \%$ & $8,94 \%{ }^{4}$ & $2,20 \%{ }^{1}$ & $4,04 \%{ }^{3}$ & $3,65 \%{ }^{5}$ & $\%$ & $2,20 \%$ & $0,64 \%$ & $9,51 \%$ \\
\hline Personal & $0,64 \%$ &, $44 \%$ & $1,28 \%$ & $4,63 \%$ & $\begin{array}{ll} & 6 \\
1,7 \% & \end{array}$ & $1,47 \%$ & $\%$ & $9,51 \%$ & $38 \%$ & $1,95 \%$ \\
\hline
\end{tabular}

The study of personal reflection allows us to draw the following conclusions: first-year students have a low level of $10.64 \%$, a level below the average was found in $21.28 \%$, the average level of personal reflection development was diagnosed in $34.04 \%$ of respondents, a level above the average of the first year representatives was not detected, the high level of personal reflection development was found in $6.38 \%$.

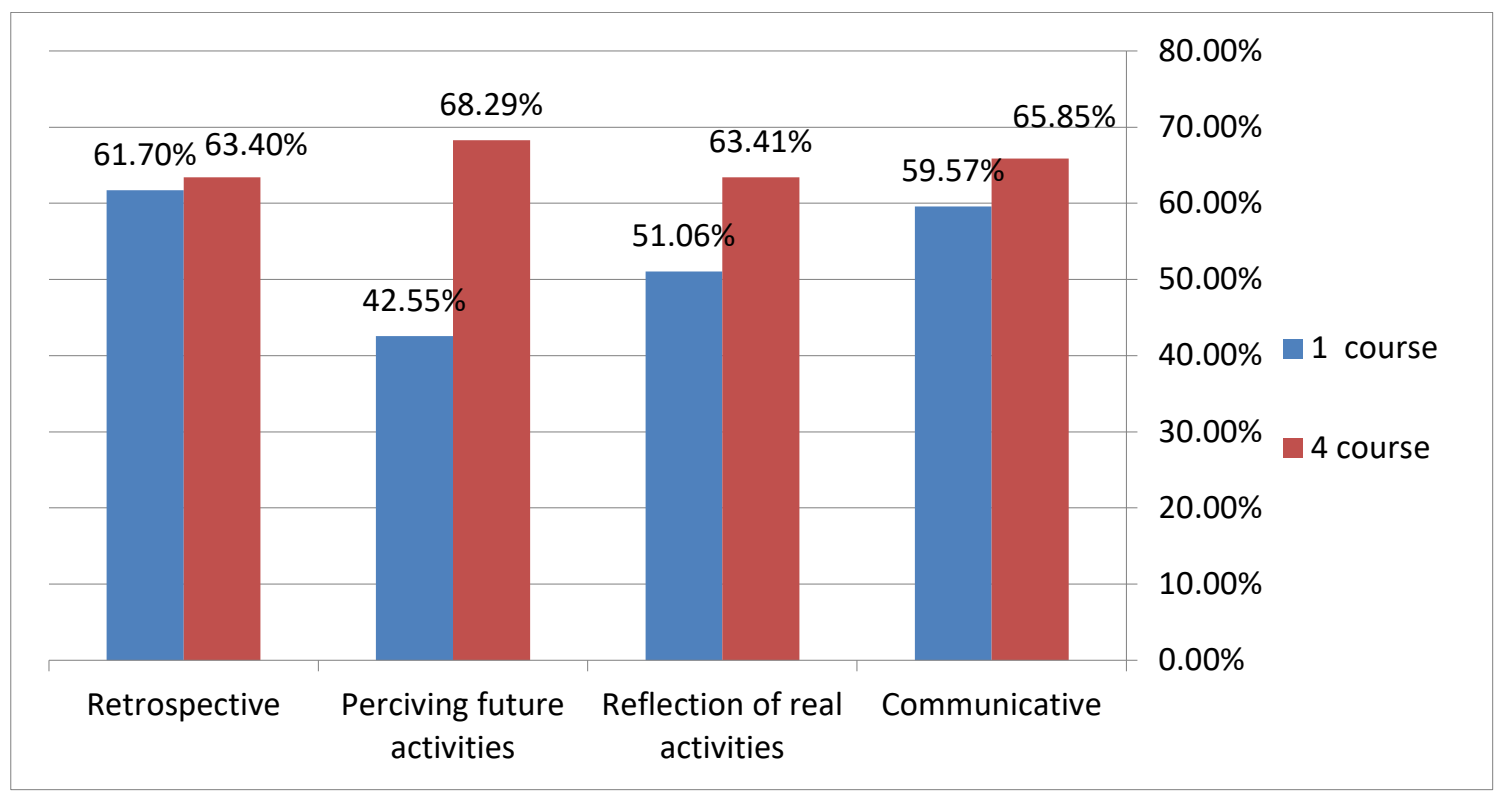

Fig. 2. Analysis of First and Fourth Year Students` Reflection Formation Source: Own results

Fourth year students have a low level of $2.44 \%$, a lower level was detected in $14.63 \%$ of students, $53.65 \%$ of respondents were diagnosed with an average level of personal reflection development, a level above the average was observed in $19.51 \%$ of students, high the level of development of personal reflection was found in $21.95 \%$ of students. Thus, among students, both first and fourth year students, the lowest results are observed on the scale of intellectual reflection, although the level of intellectual reflection reflection is higher in the fourth year than in the first year students. On other scales there is also a difference between the courses, the results of the fourth year students outweigh the results of the first year students.

The chosen methods also allow students to determine retrospective, situational and perspective reflection, as well as reflection of communication and interaction (Fig. 2). Retrospective reflection is reflected in $61.7 \%$ of first year students and $63.4 \%$ of fourth year students; situational reflection - in $51.06 \%$ of first year students and $63.41 \%$ of fourth year students; perspective reflection - in $42.55 \%$ of first year students and $68.29 \%$ of fourth year students. Communicative reflection is expressed in $59.57 \%$ of the first year and $65.85 \%$ of the fourth year. Thus, we can observe that first-year students prioritize retrospective reflection and communication, and fourth-year students perspective reflective analysis of their future activities. 
Statistical analysis, namely the Pearson correlation coefficient, revealed significant associations between the level of leadership and reflectivity, at the significance level $p=0.05$. Thus, we can conclude that there is a direct correlation between all the indicators of reflexivity and the level of leadership qualities formation, that is, the higher the level of reflexivity, the higher the level of leadership qualities, which confirms the reflective dimensions of leadership qualities.

\section{Conclusions}

All in all, leadership qualities, which we characterized as the integration of personal, social and psychological features, that help to fulfill yourself as a leader, are essential person's qualities in the modern global world. The most sensitive leadership formation period for the new generation is the time of studying at the higher educational institution. The structure of the student's leadership qualities includes a motive-sensitive component; as a group of the motives, needs for the priority setting and the readiness to the leader's activities; a cognitive component which is connected with the knowledge about leadership phenomenon and leadership qualities; an operationalactivity component which includes practical implementation of the leadership qualities in the leader's activities.

Paying attention to the reflective aspects of leadership it is proved, that the reflexive dimension of the motivational and value component of leadership is related to an awareness of the hierarchy of values, needs of motives and attitudes through personal, retrospective and situational reflection. Reflective dimensions of the cognitive component lead to knowledge of the bases of their leadership qualities in the process of personal reflection; knowledge of the limits of their knowledge and ignorance of their leadership qualities (intellectual reflection); knowledge of others' attitudes (communicative reflection); knowledge of the organization and position of participants in group interaction (cooperative reflection).

Reflexive dimensions of the operating component are related to the awareness of one's own leadership activity (personal, retrospective reflection); with an analysis of its positive aspects and complications (intellectual, situational reflection). The cooperative type of reflection is essential in this component of leadership qualities. It is proved that at the initial stage of the educational process at the university there are leadership qualities, "selforiented", which are related to personal, intellectual and retrospective reflection. At the stage of completion of the second (bachelor) level of higher education, the student's leadership qualities, directed "at others", which are conditioned by communicative, cooperative, perspective reflection, become priority. In the experimental study, the relationship and interdependence of leadership qualities and different types of reflection were proven at a significance level of $\mathrm{p}=0.05$ and hence can be perceived as relevant.

\section{References}

Anisimov OS, Refleksivnaya akmeologiya, $1^{\text {st }}$ edn. (RAGS: Moscow, 2008), 215 p.

Blanshar K, Leading at a Higher Level: Blanchard on Leadership and Creating High Performing Organizations $1^{\text {st }}$ edn. (Piter: SPb, 2008), 368 p.

Drucker PF, Effective enterprise management: a textbook, $1^{\text {st }}$ edn. (Williams: Moscow, RU, 2008), 224 p.

Fetiskin NP, Kozlov VV, Manuilov GM, Socialno- psikhologicheskaya diagnostika razvitiya lichnosti I malykh grupp, $1^{\text {st }}$ edn. (Publishing Institute of Psychotherapy: Moscow, RU, 2002), 490 p.

Karpov AV, Refleksivnaya determinaciya deyatelnosti I lichnosti, $1^{\text {st }}$ edn. (RAO: Moscow, RU, 2012), 476 p.

Owen H, Calling - Leader: A Complete Guide to Effective Leadership, $1^{\text {st }}$ edn. (Balance Business Books: Dnepropetrovsk, Ukraine, 2005), 384 p.

Palamar S, Golota N, Mashovets M, Formation of leadership qualities of future teachers of primary school in professional preparation (Atlantis Press, 2019), 220 p.

Pashukova TI, Dopira AI, Diakonov GV, Psikhologicheskoye issledovaniye. Praktikum po obschey psikhologii dlya studentov pedagogicheskykh vuzov. Uchebnoye posobiye, $1^{\text {st }}$ edn. (Publishing Institute of Practical Psychology: Moscow, 1996), 127 p.

Romanovsky OG, Leadership qualities in professional activity, 1 $1^{\text {st }}$ edn. (NTU “KPI”: Kharkiv, 2017), 143 p.

Savytska IM (2016) On formation of leadership qualities of future teachers. Bulletin of Chernihiv National Pedagogical University. Series: Pedagogical Sciences 140: 180-183.

Semenov IN, Stepanov OM (1985) Psikhologiya reflexii. Problemy I issledovaniya 2:15-26. 
Sociology: A Short Encyclopedic Dictionary. http://subject.com.ua/sociology/dict/249.html. Accessed 21 Jan 2019

Sopivnyk RV, Education of leadership qualities of students of agrarian higher educational institutions: monograph, $1^{\text {st }}$ edn. ("TsP "Comprint”: Kyiv, 2012), 514 p.

Stogdill R, Handbook of Leadership: a survey of theory and research, $1^{\text {st }}$ edn. (Free Press: New York, USA, 1974), $613 \mathrm{p}$.

Volkivska DA (2016) Razvitiye liderskogo potenciala studencheskogo aktiva v universitetskoy srede. Avtoreferat dissertacii. Kyiv: Kyivsky universitet imeni Borysa Grinchenko, 22 p.

Zhelanova VV (2017) Taxonomy of types of teacher's professional reflection: an interdisciplinary context, Pedagogical education: theory and practice. Psychology. Pedagogy 27:9-14. doi:10.1007/s11165-015-9494-6.

Zimnyaya IA, Pedagogicheskaya psikhologiya, $3^{\text {rd }}$ edn. (Logos: Moscow, 2004), 448 p. 